\title{
TEM Study of Additively Manufactured Metallic Alloys: Nickel Aluminum Bronze
}

\author{
Babak Shalchi Amirkhiz ${ }^{1}$, Dharmendra Chalasani ${ }^{2}$, Mohsen Mohammadi ${ }^{2}$ \\ 1. CanmetMATERIALS, Natural Resources Canada, Hamilton, ON, Canada. \\ 2. Marine Additive Manufacturing Centre of Excellence (MAMCE), University of New Brunswick, \\ Fredericton, NB, Canada
}

Due to rapid solidification, additively manufactured alloys possess a very fine microstructure when compared to their cast counterparts. This results in smaller grains, finer precipitates, or even a completely different sequence of phase transformations. In order to understand the fine structure of these alloys TEM should be used complementary to optical and SEM imaging to reveal the fine features within the fine dendritic microstructure commonly found in 3D-printed metallic alloys.

Nickel Aluminum Bronze (NAB) alloys are valued for their high strength combined with good ductility and toughness, high resistance to all forms of corrosion (especially, in marine atmosphere), and excellent wear, cavitation, and galling resistance. Unlike many non-ferrous alloys, NABs can undergo a wide range of solidstate phase transformations during the solidification which results in formation of numerous phases. As opposed to conventional casting processes, superior mechanical properties can be achieved by additive manufacturing (AM) that results in certain microstructural benefits such as reducing segregation, uniform distribution of precipitates, and fine grain size [1,2], which in turn could result in better mechanical and corrosion behavior.

In this work wire-arc additive manufacturing (WAAM) process was used to vertically deposit NAB on $316 \mathrm{~L}$ stainless steel plate $(10 \mathrm{~mm}$ thick) in the form of square bar that was in $16 \mathrm{~cm}$ in length and $2.5 \mathrm{~cm}$ as side., respectively. We used ion milling to prepare thin foil specimens for TEM characterization, and used TecnaiOsiris TEM operating at $200 \mathrm{kV}$. We used a variety of techniques such as STEM imaging combined with EDS elemental mapping, and selected area and convergent beam electron diffraction techniques to identify different phases.

The WAAM samples showed significantly finer and lower volume of intermetallic second-phases as compared to the cast samples. In WAAM-NAB, the $\kappa_{I I}$ and $\kappa_{\text {III }}$ phases are precipitated in the interdendritic regions (Fig. 1,2) whereas the $\kappa_{\mathrm{IV}}$ is uniformly nucleated in the $\alpha$-matrix (Fig. 3). The $\kappa_{\mathrm{II}}$ particles are globular and are of $\mathrm{Fe}_{3} \mathrm{Al}$ type; $\kappa_{\text {III }}$ is a eutectoid mixture of NiAl lamellae as seen in Fig. 1 . The very fine precipitates of $\kappa_{\mathrm{IV}}$ within the $\alpha$-matrix give rise to appearance of diffraction superlattice spots as seen in the SAD taken along [001] zone axis of the $\alpha$-matrix as seen in Fig. 3c.

Similar approach could be applied to other 3D printed metallic alloys to study their microstructure and to correlate their microstructure with mechanical and corrosion behavior [3].

References:

[1] A Hadadzadeh et al., Additive Manufacturing 23 (2018), p.108.

[2] A Hadadzadeh, BS Amirkhiz, M Mohammadi, Materials Science and Engineering: A 739 (2018), p. 295.

[3] The Authors would like to thank Natural Sciences and Engineering Research Council of Canada

(NSERC) grant number RGPIN-2016-04221, New Brunswick Innovation Foundation (NBIF) grant number

RIF 2018-005, and Atlantic Canada Opportunity Agency (ACOA)- Atlantic Innovation Fund (AIF) project number 210414. C Her Majesty the Queen in Right of Canada, as represented by the Minister of Natural Resources, 2019. 



Figure 1. STEM-HAADF and $\mathrm{Cu}, \mathrm{Ni}, \mathrm{Fe}$ composite elemental map of WAAM-NAB in an inter-dendritic region and corresponding EDS elemental maps for $\mathrm{Cu}, \mathrm{Ni}, \mathrm{Fe}$, and $\mathrm{Al}$.
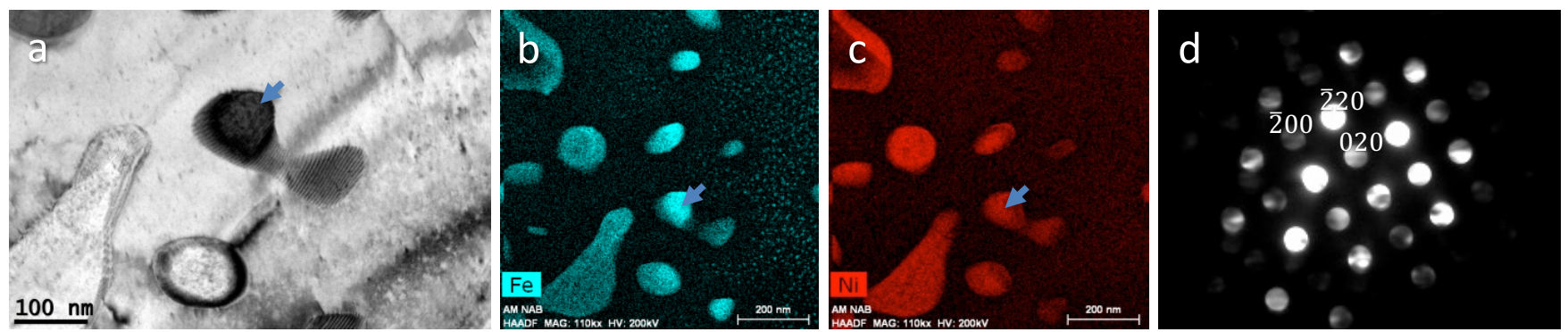

Figure 2. a) TEM bright field image showing $\kappa_{I I}$ formation within NiAl lamellae. The same precipitate is shown (arrowed) in EDS elemental maps of $\mathrm{Fe}(\mathrm{b})$ and $\mathrm{Ni}$ (c) taken from the same region, and the structure of

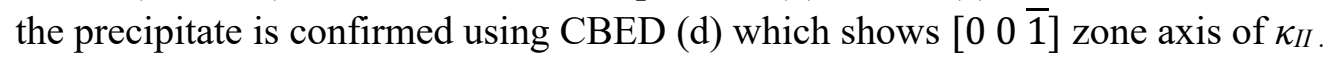
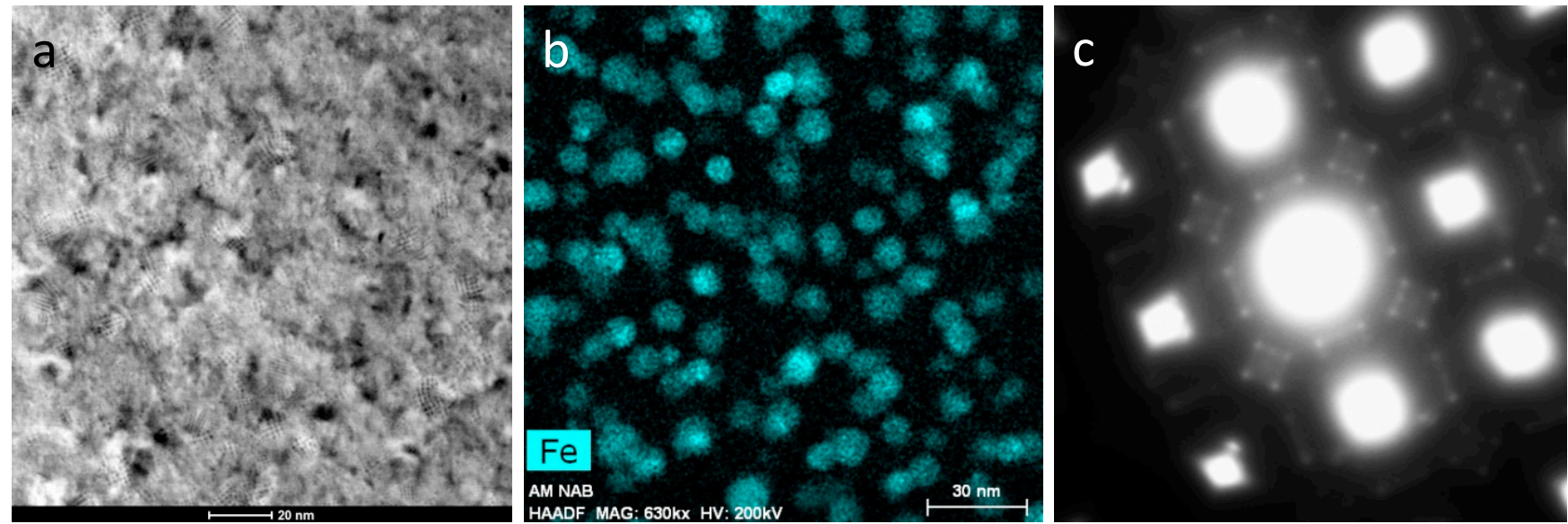

Figure 3. a) Bright field STEM image of the matrix in WAAM-NAB and b) corresponding elemental map of Fe showing $\kappa_{I V}$. Image is taken with the beam parallel to [001] zone axis of the matrix. c) Selected area diffraction pattern with the beam parallel to the [001] zone axis of $\alpha$-matrix where superlattice spots represent $\kappa_{\mathrm{IV}}$ precipitates. 